ICF1001055

\title{
LONG TERM PREDICTION OF FATIGUE LIFE FOR FRP JOINT SYSTEMS
}

\author{
Y. Miyano ${ }^{1}$, M. Nakada ${ }^{1}$, N. Sekine ${ }^{2}$, and S. W. Tsai ${ }^{3}$ \\ ${ }^{1}$ Materials System Research Laboratory, Kanazawa Institute of Technology, \\ Yatsukaho, Matto, Ishikawa 924-0838, Japan \\ ${ }^{2}$ Graduate Student, Kanazawa Institute of Technology, \\ Ohgigaoka, Nonoichi, Ishikawa 921-8501, Japan \\ ${ }^{3}$ Department of Aeronautics \& Astronautics, Stanford University, \\ Stanford, CA 94305-4035, USA
}

\begin{abstract}
The tensile constant elongation-rate (CER) and fatigue tests for GFRP/metal conical shaped joint, adhesive joint using a ductile PMMA adhesive, and bolted joint were carried out under various loading rates and temperatures. The fatigue failure loads as well as CER failure loads for these three types of GFRP joint depend clearly on loading rate and temperature. The time-temperature superposition principle holds for fatigue failure loads as well as CER failure loads for these GFRP joints, therefore the master curves for fatigue failure load can be obtained from these results. The dependence of these fatigue failure loads upon number of cycles to failure as well as time to failure and temperature can be characterized from the master curves for these GFRP joints.
\end{abstract}

\section{KEY WORDS}

GFRP, Conical shaped joint, Adhesive joint, Bolted joint, Tensile behavior, Fatigue, Life prediction, Time-temperature superposition principle

\section{INTRODUCTION}

The mechanical behavior of polymer resins exhibits time and temperature dependence, called viscoelastic behavior, not only above the glass transition temperature $T_{g}$ but also below $T_{g}$. Thus, it can be presumed that the mechanical behavior of polymer composites also significantly depends on time and temperature even below $\mathrm{T}_{\mathrm{g}}$ which is within the normal operating temperature range.

The time-temperature dependence of the tensile and flexural strengths under constant strain-rate (CSR) and fatigue loadings for various kinds of FRP has been studied in our previous papers [1-8]. It was observed that the fracture modes are almost identical under two types of loading over a wide range of time and temperature, and the same time-temperature superposition principle holds for CSR and fatigue strengths. Therefore, the master curves of fatigue strength for these FRP were obtained. 
In this paper, the tensile fatigue tests as well as tensile constant elongation-rate (CER) tests for GFRP/metal conical shaped joint, GFRP/metal adhesive joint using a ductile PMMA adhesive, and GFRP/metal bolted joint are carried out under various loading rates and temperatures. The time and temperature dependencies of tensile fatigue behavior for these three GFRP joints are discussed.

\section{EXPERIMENTAL PROCEDURE}

\section{Preparation of GFRP joints}

The conical shaped joint is made from a unidirectional GFRP rod, metal end fittings (42CrMo4), and bonding resin as shown in Fig.1. The unidirectional GFRP rod consists of E-glass fibers and epoxy resin, and is produced by pultrusion molding. The bonding resin consists of epoxy resin and silica. The bonding resin taper and the bonding length are respectively $6^{\circ}$ and $25 \mathrm{~mm}$.

The adhesive joint is made from a GFRP pipe, ductile cast iron rod (600-3), and adhesive resin as shown in Fig.2. The GFRP pipe consists of glass cloth and epoxy resin, and is produced by tape winding method. An adhesive resin is a ductile PMMA resin. The adhesive resin thickness and length are respectively $4 \mathrm{~mm}$ and $28 \mathrm{~mm}$.

The bolted joint is constructed from a GFRP pipe, steel rod (C45), and bolt as shown in Fig.3. The GFRP pipe is the same to that for adhesive joint. The GFRP pipe is joined to steel rod by two bolts. One is $1 / 4-20$ UNC bolt with small washer, where the thickness of GFRP pipe is $3 \mathrm{~mm}$. The other is M $8 \times 1.25$ bolt with large washer, where the thickness of GFRP pipe is $5 \mathrm{~mm}$.

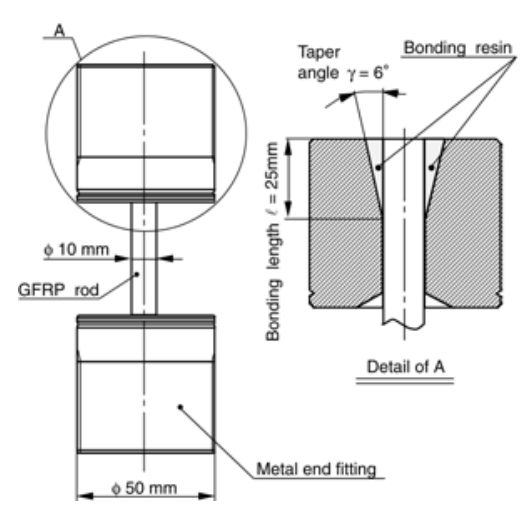

Fig.1 Conical shaped joint

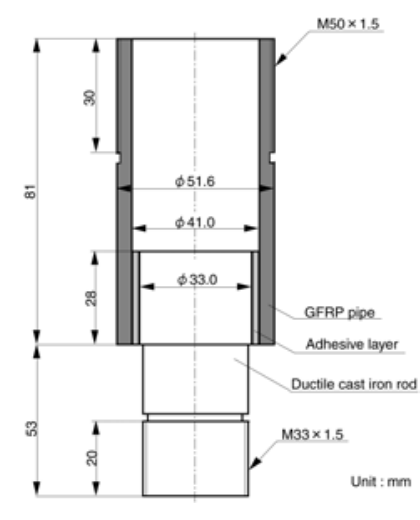

Fig.2 Adhesive joint

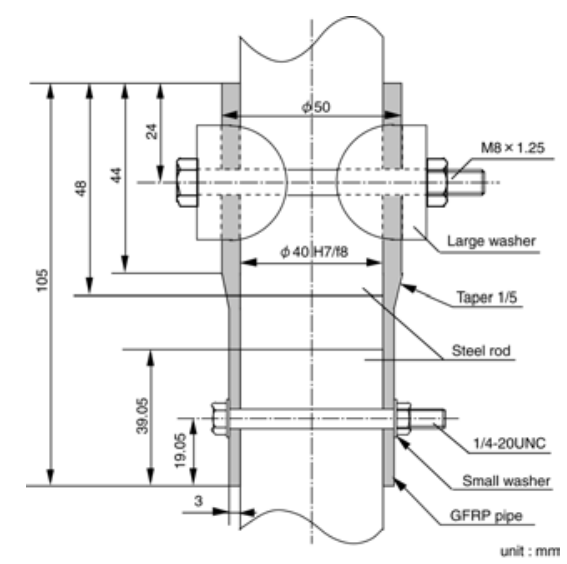

Fig.3 Bolted joint

\section{Test procedure}

The tensile CER tests were carried out under various loading rates and temperatures using an Instron type testing machine. The loading rates were $0.01,1$ and $100 \mathrm{~mm} / \mathrm{min}$. The tensile fatigue tests were carried out under various temperatures at two frequencies $\mathrm{f}=5$ and $0.05 \mathrm{~Hz}$ using an electro-hydraulic servo testing machine. Load ratio R (minimum load/maximum load) was 0.05 . 


\section{RESULTS AND DISCUSSION}

\section{Master curve of CER failure load}

Figures 4 and 5 show the master curves of tensile CER failure load and time-temperature shift factors for three cases: (a) conical shaped joint, (b) adhesive joint, and (c) bolted joint.

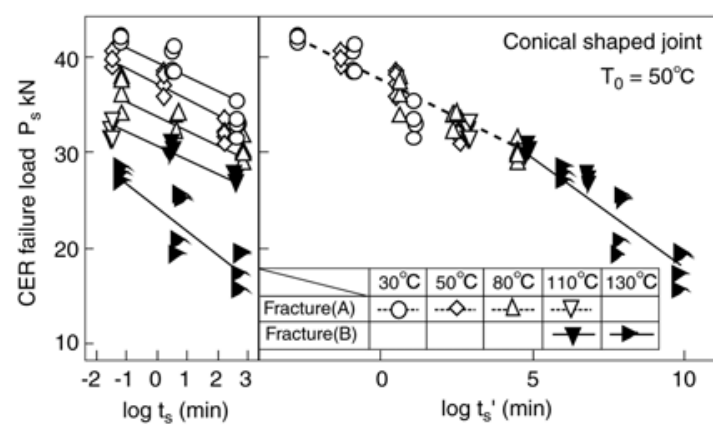

(a) Conical shaped joint

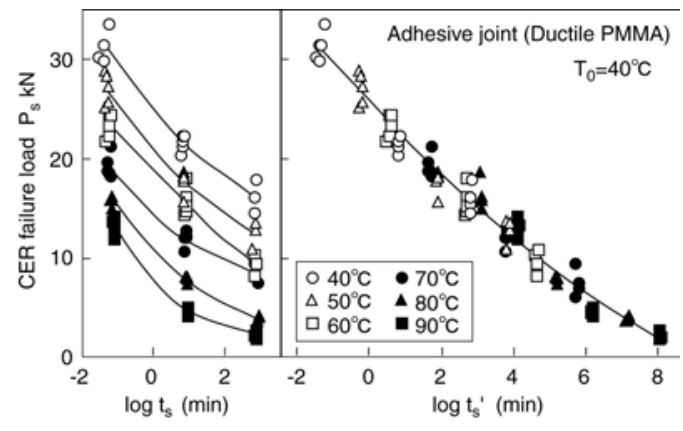

(b) Adhesive joint

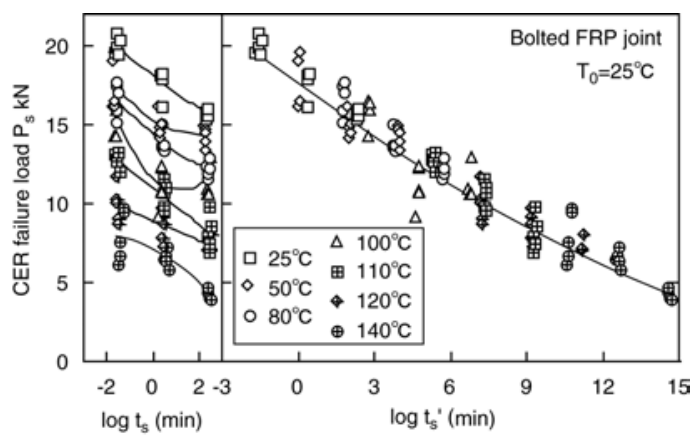

(c) Bolted joint

Fig.4 Master curves of CER failure load for three types of GFRP joint

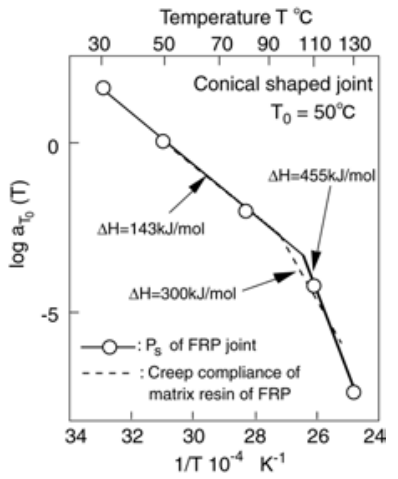

(a) Conical shaped joint

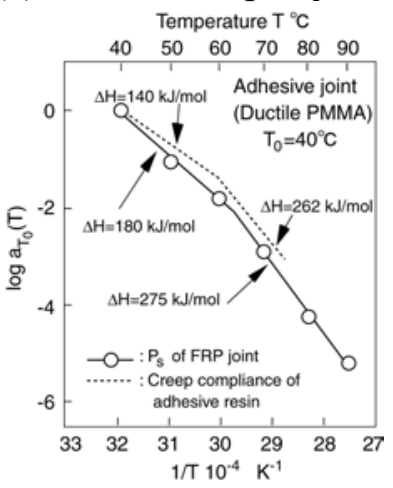

(b) Adhesive joint

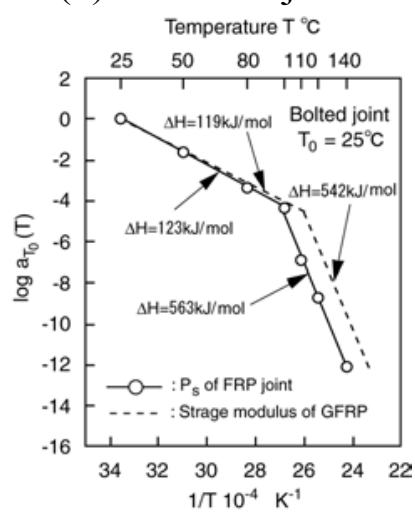

(c) Bolted joint

Fig.5 Time-temperature shift factors of CER failure load for three types of GFRP joint

The left sides of Fig.4 show the CER failure load $P_{s}$ versus time to failure $t_{s}$, the time period from initial loading to maximum load. The master curves for each $\mathrm{P}_{\mathrm{s}}$ were constructed by shifting $\mathrm{P}_{\mathrm{s}}$ at various constant temperatures along the $\log$ scale of $t_{s}$ so that they overlap on $P_{s}$ at the reference temperature $T_{0}$ or on each other to form a single smooth curve as shown in the right sides of this figure. Since the smooth master curves for each $\mathrm{P}_{\mathrm{s}}$ can be obtained, the time-temperature superposition principle is applicable for 
each $\mathrm{P}_{\mathrm{s}}$.

The time-temperature shift factors $\mathrm{a}_{\mathrm{To}}(\mathrm{T})$ for each $\mathrm{P}_{\mathrm{s}}$ obtained experimentally in Fig. 4 are plotted respectively in Fig.5. These $\mathrm{a}_{\mathrm{To}}(\mathrm{T})$ agree with those for the viscoelastic stress-strain relationship of the matrix resin of GFRP or adhesive resin for the corresponding GFRP joint indicated by dotted lines, which are described by two Arrhenius' equations with different activation energies $\Delta \mathrm{H}$.

The fracture of conical shaped joint occurs at the GFRP rod within the contact area of the bonding resin. The failure mode changed with temperature. In the region of low temperature, this joint fails coaxially at the surface of GFRP rod, and then the shearing crack propagates transversely in the GFRP rod (Fracture A). In the region of high temperature, this joint also fails coaxially at the surface of GFRP rod, and then the shearing crack propagates longitudinally in the GFRP rod (Fracture B). The fracture modes A and B for this conical shaped joint can be classified clearly on the master curve as shown in Fig.4 (a). The fracture of adhesive joint occurred in the adhesive resin nearby the interface between cast iron rod and adhesive resin in all region of temperature tested. The fracture of bolted joint occurs at GFRP pipe in the vicinity of $1 / 4-20 \mathrm{UNC}$ bolt in all region of temperature tested. The bearing failure of GFRP pipe was observed initially, and then cracks occurred along circumference direction of GFRP pipe from the right and left edges of hole.

From these results, the time-temperature dependence of CER failure load for the conical shaped joint, adhesive joint, and bolted joint is controlled by the viscoelastic behavior of the matrix resin of GFRP or adhesive resin for the corresponding GFRP joint.

\section{Master curve of fatigue failure load}

We turn now the fatigue failure load $\mathrm{P}_{\mathrm{f}}$ and regard it either as a function of the number of cycles to failure $\mathrm{N}_{\mathrm{f}}$ or of the time to failure $t_{\mathrm{f}}=\mathrm{N}_{\mathrm{f}} / \mathrm{f}$ for a combination of frequency $f$, temperature $T$ and denote them by $\mathrm{P}_{\mathrm{f}}$ $\left(N_{f}, f, T\right)$ or $P_{f}\left(t_{f}, f, T\right)$. Further, we consider the CER failure load $P_{s}\left(t_{f}, T\right)$ as the fatigue failure load at $\mathrm{N}_{\mathrm{f}}=1 / 2, \mathrm{R}=0$, and $\mathrm{t}_{\mathrm{f}}=1 /(2 \mathrm{f})$.

To describe the master curve of $\mathrm{P}_{\mathrm{f}}$, we need the reduced frequency $\mathrm{f}^{\prime}$ in addition to the reduced time to failure $t_{f}^{\prime}$, each defined by

$$
\left.f^{\prime}=f \cdot a_{T_{0}}\right]_{T} \zeta \quad t_{f}{ }^{\prime}=\frac{t_{f}}{a_{T_{0}} \operatorname{Dog}} \frac{N_{f}}{f^{\prime}}
$$

We introduce two alternative expressions for the master curve: $\mathrm{P}_{\mathrm{f}}\left(\mathrm{t}_{\mathrm{f}}^{\prime}, \mathrm{f}^{\prime}, \mathrm{T}_{0}\right)$ and $\mathrm{P}_{\mathrm{f}}\left(\mathrm{t}_{\mathrm{f}}^{\prime}, \mathrm{N}_{\mathrm{f}}, \mathrm{T}_{0}\right)$. In the latter expression, the explicit reference to frequency is suppressed in favor of $\mathrm{N}_{\mathrm{f}}$. Note that the master curve of fatigue failure load at $\mathrm{N}_{\mathrm{f}}=1 / 2$ is regarded as the master curve of CER failure load. Equation (1) enables one to construct the master curve for an arbitrary frequency from the tests at a single frequency under various temperatures.

Figure 6 displays the fatigue failure load $\mathrm{P}_{\mathrm{f}}$ versus the number of cycles to failure $\mathrm{N}_{\mathrm{f}}\left(\mathrm{P}_{\mathrm{f}}-\mathrm{N}_{\mathrm{f}}\right)$ curves at a frequency $\mathrm{f}=5 \mathrm{~Hz}$ for three cases: (a) conical shaped joint, (b) adhesive joint, and (c) bolted joint. The CER failure loads regarded as the fatigue failure load at $\mathrm{N}_{\mathrm{f}}=1 / 2$ are included in these figures. The fracture mode of conical shaped joint is also classified into two modes on the $\mathrm{P}_{\mathrm{f}}-\mathrm{N}_{\mathrm{f}}$ curves as shown in Fig.6 (a). 
In Fig.7, $\mathrm{P}_{\mathrm{f}}$ versus the reduced time to failure $\mathrm{t}_{\mathrm{f}}$ ' curves for several reduced frequencies $\mathrm{f}^{\prime}$ at the reference temperature $T_{0}$ are depicted by thin lines, which are obtained by converting $\mathrm{N}_{\mathrm{f}}$ of Fig. 6 into $\mathrm{t}_{\mathrm{f}}$ ' using Eq.(1) and the shift factor for CER failure load. The master curves of $\mathrm{P}_{\mathrm{f}}$ for fixed $\mathrm{N}_{\mathrm{f}}$ indicated by thick lines are constructed by connecting the points of the same $\mathrm{N}_{\mathrm{f}}$ on the curves of each $f^{\prime}$ indicated by thin lines in these figures.

The $\mathrm{P}_{\mathrm{f}}-\mathrm{N}_{\mathrm{f}}$ curves at $\mathrm{f}=0.05 \mathrm{~Hz}$ predicted from Fig. 7 are displayed in Fig. 8 together with test data. Since the $\mathrm{P}_{\mathrm{f}}-\mathrm{N}_{\mathrm{f}}$ curves predicted on the basis of the superposition principle capture test data satisfactorily, the time-temperature superposition principle for CER failure load also holds for fatigue failure load. Therefore, the validity for the construction of master curves of fatigue failure load using the time-temperature shift factor for CER failure load is confirmed.

\section{Comparison of the master curves of fatigue failure load}

From the master curves of tensile fatigue failure load for three types of GFRP joint as shown in Fig.7, the time-temperature dependent fatigue behavior for these three types of GFRP joint can be characterized. The tensile fatigue failure load for conical shaped joint depends slightly on time to failure and temperature, however the fatigue failure load decreases clearly with increasing $\mathrm{N}_{\mathrm{f}}$. The fatigue failure loads for adhesive joint and for bolted joint depend clearly on time to failure and temperature, however these fatigue failure loads decrease scarcely with increasing $\mathrm{N}_{f}$.

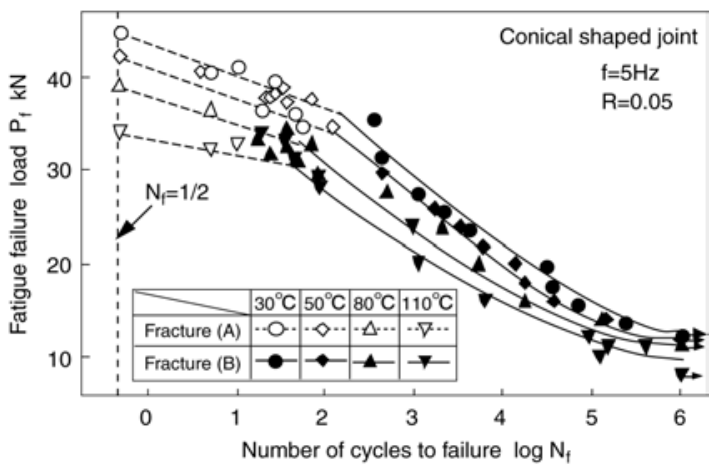

(a) Conical shaped joint

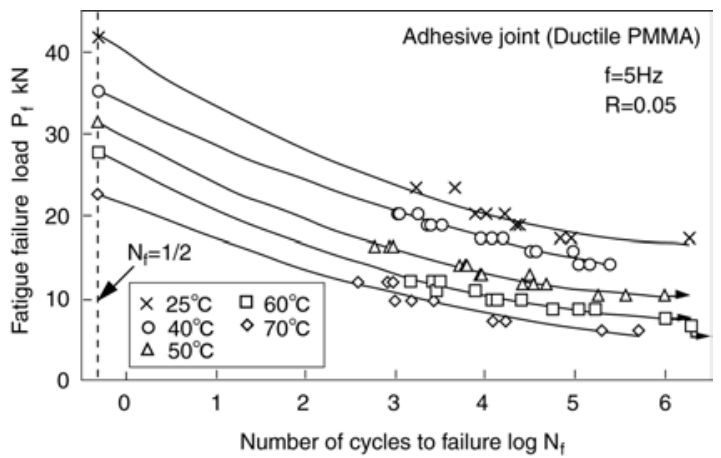

(b) Adhesive joint

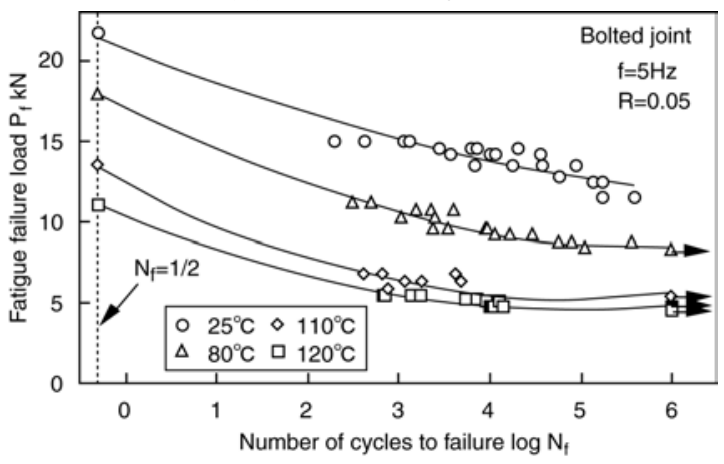

(c) Bolted joint

Fig.6 $\mathrm{P}_{\mathrm{f}}-\mathrm{N}_{\mathrm{f}}$ curves for three types of GFRP joint at frequency $\mathrm{f}=5 \mathrm{~Hz}$

\section{CONCLUSION}

The time and temperature dependence of tensile fatigue behavior for GFRP/metal conical shaped joint, adhesive joint using a ductile PMMA adhesive, and bolted joint are determined experimentally. The time-temperature superposition principle holds for the tensile fatigue failure loads as well as CER failure loads for all of these GFRP joints, therefore, the master curves of fatigue failure load for these GFRP joints can be obtained. The master curves of fatigue failure load show very characteristic behavior due to the structure and the combination of materials of GFRP joints. 


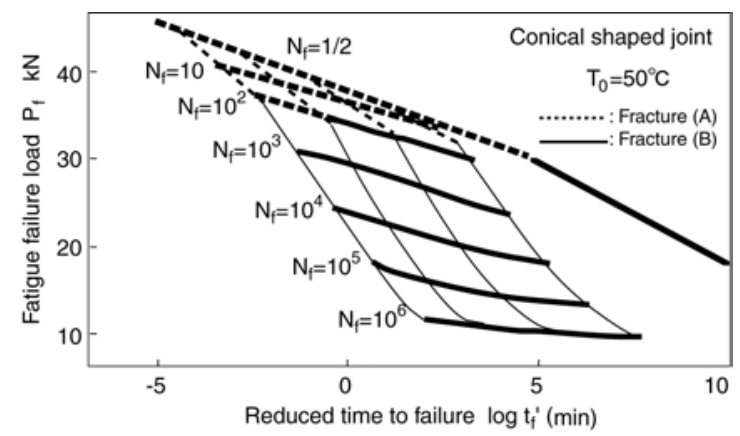

(a) Conical shaped joint

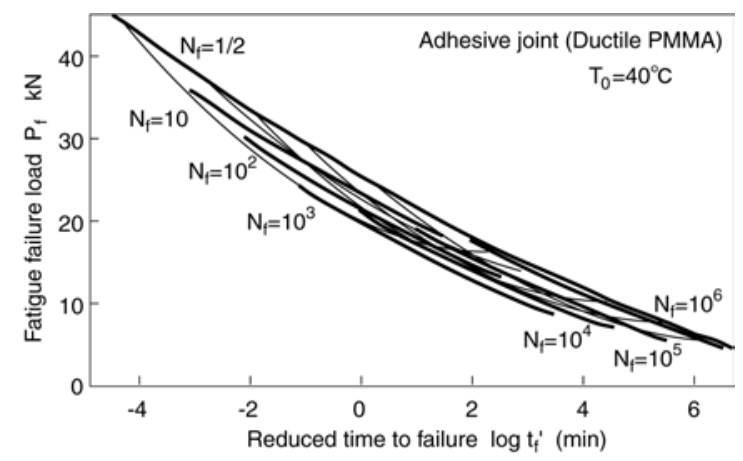

(b) Adhesive joint

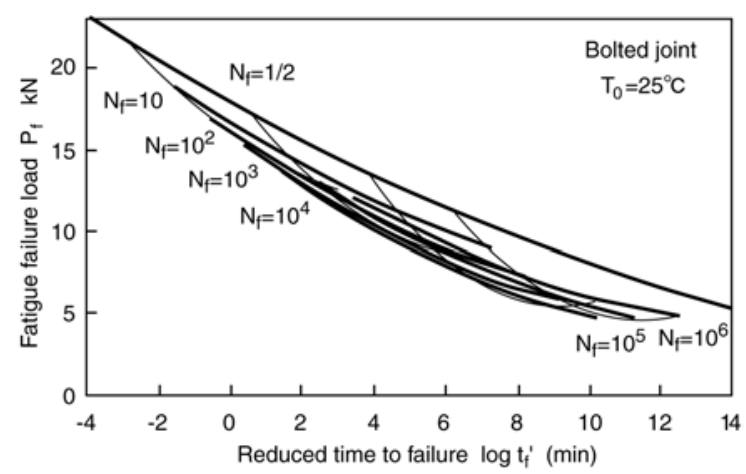

(c) Bolted joint

Fig.7 Master curves of fatigue failure load for three types of GFRP joint

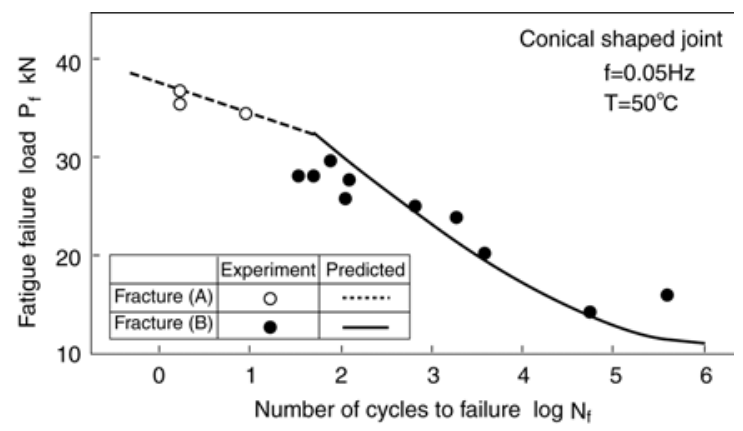

(a) Conical shaped joint

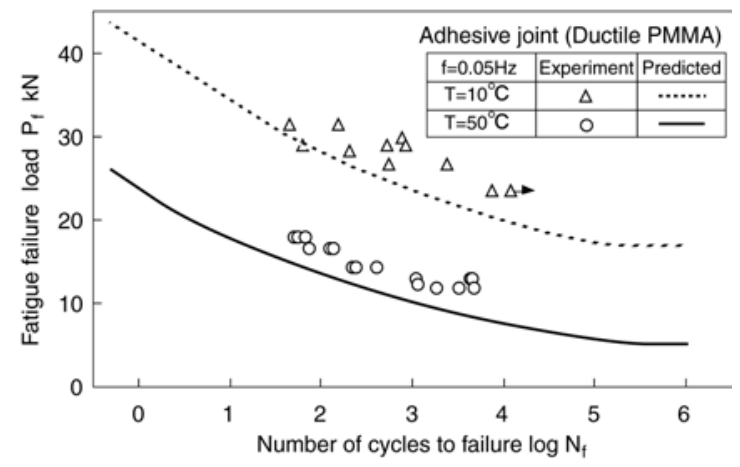

(b) Adhesive joint

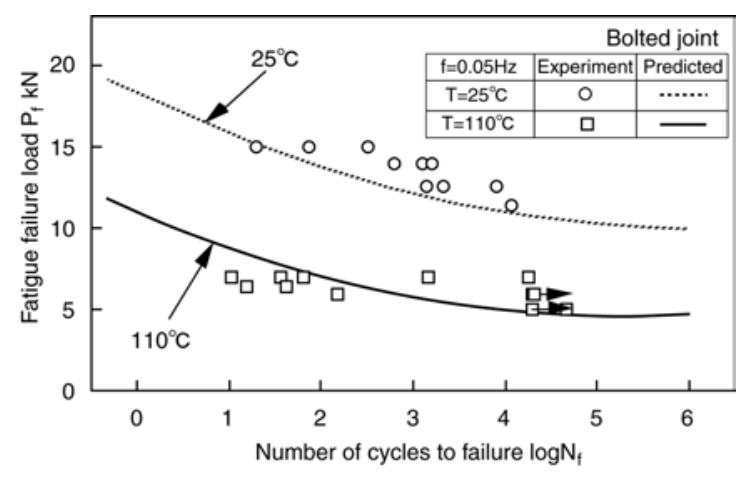

(c) Bolted joint

Fig.8 $\mathrm{P}_{\mathrm{f}}-\mathrm{N}_{\mathrm{f}}$ curves for three types of GFRP joint at frequency $\mathrm{f}=0.05 \mathrm{~Hz}$

\section{REFERENCES}

1. Aboudi, J. and Cederbaum, G. (1989). Composite Structures, 12, p.243.

2. Ha, S. K. and Springer, G. S. (1989). J. Composite Materials, 23, p.1159.

3. Sullivan, J.L. (1990). Composite Science and Technology, 39, p.207.

4. Miyano, Y., Kanemitsu, M., Kunio, T. and Kuhn, H.J. (1986). Composite Materials, 20, p.520.

5. Miyano, Y., McMurray, M. K., Enyama, J. and Nakada, M. (1994). J. Composite Materials, 28, p.1250.

6. Miyano, Y., McMurray, M. K., Kitade, N., Nakada, M. and Mohri, M. (1994). Advanced Composite Materials, 4, p.87.

7. Miyano, Y., Nakada, M. and McMurray, M. K. (1995). J. Composite Materials, 29, p.1808.

8. Miyano, Y., M. Nakada, M. K. McMurray, and R. Muki, J. Composite Materials, 31 (1997), p.619. 